\title{
MYH9 disorder: diagnosis using immunofluorescence and genetic testing in Thai children and adolescents with macrothrombocytopenia
}

RUNGROTE NATESIRINILKUL ${ }^{1}$, Darintr Sosothikul ${ }^{2}$, Patcharee Komwilaisak ${ }^{3}$, Bunchoo Pongtanakul $^{4}$, Nattee Narkbunnam ${ }^{4}$, Najwa Yudhasompop ${ }^{5}$, Pimsiri Mekjaruskul ${ }^{6}$, Pimjai Niparuck $^{7}$, Kochawan Boonyawat ${ }^{7}$, Shinji Kunishima ${ }^{8}$, and Nongnuch Sirachainan ${ }^{7}$

${ }^{1}$ Chiang Mai University Faculty of Medicine

${ }^{2}$ Chulalongkorn University

${ }^{3}$ Khon Kaen University

${ }^{4}$ Mahidol University Faculty of Medicine Siriraj Hospital Department of Pediatrics

${ }^{5}$ Hatyai Hospital

${ }^{6}$ Maharat Nakhon Ratchasima Hospital

${ }^{7}$ Mahidol University Faculty of Medicine Ramathibodi Hospital

${ }^{8}$ Gifu University

October 1, 2020

\begin{abstract}
MYH9 disorder is characterized by macrothrombocytopenia with or without granulocyte DÖhle body-like inclusion bodies. Diagnosis is made by immunofluorescence analysis and genetic study of the MYH9 gene. Our collaborative study between Thailand and Japan began with 67 Thai patients with macrothrombocytopenia. Of these, 11 patients(16.4\%), aged 4 months22 years with platelet counts ranging from 2,000-99,000/uL were diagnosed with MYH9 disorder. MYH9 gene mutations occurred in exons 1,16,30,38,40. One novel mutation was identified (c.4338T >C, p.F1446A). The results indicate that patients with macrothrombocytopenia should be tested for $M Y H 9$ disorder in order to avoid misdiagnosis to the other diseases, such as chronic immune thrombocytopenia.
\end{abstract}

\section{Patients with mutations in the Head domain of the $M Y H 9$ gene}

Patients 1-6 presented at the age of [?]1 year. They were diagnosed with alloimmune thrombocytopenia (patients 3, 5 and 6), or cITP (patients 1 and 2). Their platelet count range was 2,000-65,000/uL. Patients 1-3 had mucocutaneous bleeding. Patients 1 and 6 were treated with prednisolone while patients 3 and 5 received intravenous immunoglobulin. Patient 4 was initially suspected of MYH9 disorder because granulocyte IB were observed by a hematologist from TMSG. IFA demonstrated small diffuse precipitation in all patients except patient 6 , who had small-to-medium diffuse precipitation. Five out of six patients had mutations in exon 1, of which p.S96L is the most common (Table 1 and Figure 1).

Non-HMs were identified in patients 1, 3 and patient 6 . The hearing test of patient 6 , at 5 years old, showed mixed hearing loss (Right ear: hearing frequency $1 \mathrm{kHz}$ at $22 \mathrm{~dB}$ for air and $30 \mathrm{~dB}$ for bone, Left ear: hearing frequency $4 \mathrm{kHz}$ at $40 \mathrm{~dB}$ ). This patient had a high urine protein/creatinine ratio of 0.49 and had been treated with an angiotensin inhibitor after diagnosis.

Patients with mutations in the Tail domain of the $M Y H 9$ gene 
Patients 7-11 presented from birth to 20 years of age. Their platelet count range was 3,000-99,000/ $\mu$ L. All were diagnosed with cITP and treated with prednisolone, except patient 10. Mild bleeding symptoms were reported in patients 7 and 8. Granulocyte IB were found in all patients except patient 7. IFA revealed medium diffuse precipitation in patients 7-9, and large localized precipitation in patients 10 and 11 . Genetic testing revealed mutations in exon 30,38 and 40. Mutations in exon 30 were the most common, including a novel p.F1446A mutation (Table 1 and Figure 1).

Non-HMs were demonstrated in patients 8 and 9, cousins who carried a similar mutation. Patient 8 had cataracts in both eyes. Patient 9 , the older cousin, had microscopic hematuria, cataracts in both eyes, and mild sensorineural hearing loss in both ears (hearing frequency $4 \mathrm{kHz}$ : Right ear at $23 \mathrm{~dB}$, Left ear at 30 $\mathrm{dB})$.

Family history was demonstrated in four patients: patients 8 and 9 (cousins described above), and patients 5 and 11, who each had a parent with thrombocytopenia and similar MYH9 mutations.

\section{DISCUSSION}

Our investigation found that it is important to observe granulocyte IB carefully and to test for $M Y H 9$ disorder in patients with unknown causes of macrothrombocytopenia, since $17 \%$ of our macrothrombocytopenia patients were ultimately diagnosed with $M Y H 9$ disorder. A previous study had findings that support this: $12.4 \%$ of patients with thrombocytopenia, tested by targeted next generation sequencing of 27 common genes, were found to have $M Y H 9$ disorder ${ }^{11}$. Testing for $M Y H 9$ disorder takes on even greater importance when we consider that many patients are believed to be undiagnosed due to mild bleeding symptoms. ${ }^{1,12}$ This is supported by our findings, since 6 out of 11 patients withMYH9 disorder had no bleeding symptoms at all, and the others had only mild symptoms.

Different methods can be used to identify patients with MYH9disorder, though their reliability varies. Specifically, MPV, a parameter on most automated blood cell counters, can indicate platelet size, but only half of our patients whose MPV was measured had MPV that would indicate giant platelets (i.e., [?]11 fL). In addition, relying on family history to identify patients who might have MYH9 disorder is unreliable since $30 \%$ of patients have previously been reported as sporadic cases ${ }^{5}$ and our report demonstrated that 7 out of $11(64.0 \%)$ patients had no family history of thrombocytopenia.

Therefore, to ensure diagnosis of MYH9 disorder, according to the results of our study, observation of platelet size and granulocyte IB on PBS were the most useful screening tests, despite their drawbacks: all patients had large or giant platelets and 9 out of 11 patients had granulocyte IB. Definitive diagnosis can then come from IFA of the NMMHC-IIA since IFA is sensitive and specific in detecting $M Y H 9$ disorder. Mutation analysis is also important to determine the prognosis of patients. IFA can locate mutations in the MYH9 gene according to the patterns of localization: type I, large oval-spindle precipitation usually associates with mutations in the tail domain (exons 1-16) and types II and III, small to medium-sized circleoval precipitation, usually associate with mutations in the head domain (exons 17-40). ${ }^{12}$ Since the MYH9 gene contains 40 exons, Sanger sequencing of all exons is quite time consuming and increases the cost of investigation. The present report demonstrated patterns of IF localizations that mostly correlated with the site of mutations. Specifically, 6 patients with small diffuse to medium localization patterns had common mutations in the head domain, and 5 patients with medium to large localization patterns had mutations in the tail domain.

Our findings regarding the age at which non-HMs occur are in line with previous research. Specifically, 3 younger patients (ages 2, 3 and 11) with non-HMs had mutations in the head domain (exons 1 and 16), similar to previous reports where mutations in the head domain were associated with non-HMs, especially p.R702C, which occurs in younger age groups, ${ }^{13-17}$ and p.S96L and p.W33R. ${ }^{18-23}$ Likewise, 2 older patients, aged 15 and 19, had non-HMs in the tail domain (exon 30), in agreement with previous studies that found tail domain mutations were associated with non-HMs in older age groups. ${ }^{2,14,18}$ This cohort demonstrated a novel mutation in the tail domain, p.F1446A that associated with non-HMs in adolescent age group. 


\section{CONCLUSION}

Increased diagnosis of MYH9 disorder was made possible by applying using appropriate laboratory techniques. The simplest screening approach is the observation of PBS. IFA, meanwhile, is the gold standard for diagnosing MYH9 disorder, with the added benefit of guiding the location of MYH9 gene mutations. Following this protocol will greatly increase the likelihood of diagnosing MYH9 disorder.

\section{ACKNOWLEDGEMENTS}

The authors would like to thank Professor Takeshi Sekine, who is one of the pioneers in the initiation of investigations in Thailand. We would also like to thank the members of the Thai Macrothrombocytopenia Group, consisting of Somjai Kanjanapongkul from Queen Sirikit National Institute of Child Health, Bangkok, Thirachit Chotsampancharoenfrom Prince of Songkla University, Songkhla, Chanchai Trivareefrom Phramongkutklao Hospital, Bangkok, Siranee Wongruangsri from Lampang Hospital, Lampang, Pacharapan Surapolchai from Thammasart University, Bangkok, Sumonmaln Klamchuen from Sunpasitthiprasong Hospital, Ubon Ratchathani, Saranya Busakornruangrat from Somdejprapinklao Hospital, Bangkok, Kittima Kanchanakamhaeng from Sawanpracharak Hospital, Nakhon Sawan and Nattaporntira Phalakornkul from Bhumibol Adulyadej Hospital, Bangkok. This study is supported by the Multicenter Research Grant from the Thai Society of Hematology

\section{CONFLICT OF INTEREST}

The authors state no conflicts of interest.

\section{ORCID}

Rungrote Natesirinilkul https://orcid.org/0000-0002-9840-3443

Darintr Sosothikul https://orcid.org/0000-0003-1097-3482

Patcharee Komwilaisak https://orcid.org/0000-0002-6804-9121

Bunchoo Pongtanakulhttps://orcid.org/ 0000-0003-4204-0118

Pimjai Niparuckhttps://orcid.org/0000-0002-9422-9353

Kochawan Boonyawathttps://orcid.org/ 0000-0003-3475-9173

Shinji Kunishimahttps://orcid.org/ 0000-0001-9212-0082

Nongnuch Sirachainan https://orcid.org/0000-0001-8039-5476

\section{REFERENCES}

1. Noris P, Spedini P, Belletti S, Magrini U, Balduini CL. Thrombocytopenia, giant platelets, and leukocyte inclusion bodies (May-Hegglin anomaly): clinical and laboratory findings. Am J Med. 1998;104(4):355-360.

2. Althaus K, Greinacher A. MYH9-related platelet disorders. Semin Thromb Hemost. 2009;35(2):189203.

3. May R. Leukocyteneinschlusse. Deutsch Arch Klin Med.1909;96:1-6.

4. Hegglin R. Gleichzeitige konstitutionelle veranderungen an neurtophilen und thrombocyten. Helv Med Acta. 1945;12:439-440.

5. Heath KE, Campos-Barros A, Toren A, et al. Nonmuscle myosin heavy chain IIA mutations define a spectrum of autosomal dominant macrothrombocytopenias: May-Hegglin anomaly and Fechtner, Sebastian, Epstein, and Alport-like syndromes. Am J Hum Genet . 2001;69(5):1033-1045.

6. Saito H, Kunishima S. Historical hematology: May-Hegglin anomaly. Am J Hematol. 2008;83(4):304306. 
7. Kunishima S, Matsushita T, Shiratsuchi M, et al. Detection of unique neutrophil non-muscle myosin heavy chain-A localization by immunofluorescence analysis in MYH9 disorder presented with macrothrombocytopenia without leukocyte inclusions and deafness. Eur J Haematol. 2005(1);74:1-5.

8. Kunishima S, Matsushita T, Kojima T, et al. Immunofluorescence analysis of neutrophil nonmuscle myosin heavy chain-A in MYH9 disorders: association of subcellular localization with MYH9 mutations. Lab Invest. 2003;83(1):115-122.

9. Balduini CL, Savoia A, Seri M. Inherited thrombocytopenias frequently diagnosed in adults. $J$ Thromb Haemost . 2013;11(6):1006-1019.

10. Thakral B, Rojanapremsuk T, Saluja K, Eldibany M. Misdiagnosed MYH9 related inherited macrothrombocytopenia with an inadvertent splenectomy. Pathology. 2015;47(4):377-379.

11. Rabbolini DJ, Chun Y, Latimer M, et al. Diagnosis and treatment of MYH9- RD in an Australasian cohort with thrombocytopenia. Platelets . 2018;29(8):793-800.

12. Yoshinari M, Kunishima S, Miyabayashi S, Saito H, Tsuchiya S. A unique immunofluorescence method promotes accurate diagnosis in MYH9 disorders: a case report. J Pediatr Hematol Oncol.2004;26(9):579-583.

13. Kodama R, Taketani T, Kunishima S, et al. A rare case of MYH9 disorders presenting with macrothrombocytopenia and deafness caused by MYH9-R702C mutation.Thromb Res. 2009;124(4):508-511.

14. Wasano K, Matsunaga T, Ogawa K, Kunishima S. Late onset and high-frequency dominant hearing loss in a family with MYH9 disorder. Eur Arch Otorhinolaryngol.2016;273(11):3547-3552.

15. Murayama S, Akiyama M, Namba H, Wada Y, Ida H, Kunishima S. Familial cases with MYH9 disorders caused by MYH9 S96L mutation.Pediatr Int. 2013;55(1):102-104.

16. Pecci A, Klersy C, Gresele P, et al. MYH9 disease: a novel prognostic model to predict the clinical evolution of the disease based on genotype-phenotype correlations. Hum Mutat. 2014;35(2):236-247.

17. Sirachainan N, Komwilaisak P, Kitamura K, Hongeng S, Sekine T, Kunishima S. The first two cases of MYH9 disorders in Thailand: an international collaborative study. Ann Hematol.2015;94(4):707-709.

18. Arrondel C, Vodovar N, Knebelmann B, et al. Expression of the nonmuscle myosin heavy chain IIA in the human kidney and screening for MYH9 mutations in Epstein and Fechtner syndromes. $J$ Am Soc Nephrol. 2002;13(1):65-74.

19. Dong F, Li S, Pujol-Moix N, et al. Genotype-phenotype correlation in MYH9 thrombocytopenia. $B r J$ Haematol. 2005;130(4):620-627.

20. Sun XH, Wang ZY, Cao LJ, et al. Clinical features and gene analyses of six patients with MYH9 disease.Zhonghua Xue Ye Xue Za Zhi. 2012;33(7):552-555.

21. Sun XH, Wang ZY, Yang HY, et al. Clinical, pathological, and genetic analysis of ten patients with MYH9 disease. Acta Haematol. 2013;129(2):106-113.

22. Saposnik B, Binard S, Fenneteau O, et al. Mutation spectrum and genotype-phenotype correlations in a large French cohort of MYH9-Related Disorders. Mol Genet Genomic Med.2014;2(4):297-312.

23. Pecci A, Verver EJ, Schlegel N, et al. Cochlear implantation is safe and effective in patients with MYH9-related disease. Orphanet J Rare Dis. 2014;9:100.

\section{Hosted file}

Table 1.pdf available at https://authorea.com/users/362815/articles/483828-myh9-disorderdiagnosis-using-immunofluorescence-and-genetic-testing-in-thai-children-and-adolescentswith-macrothrombocytopenia 

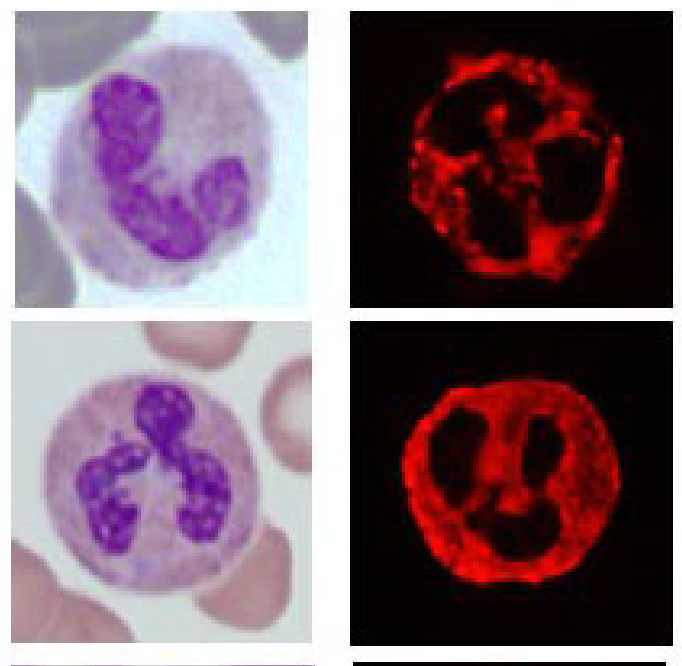

Patient \#1

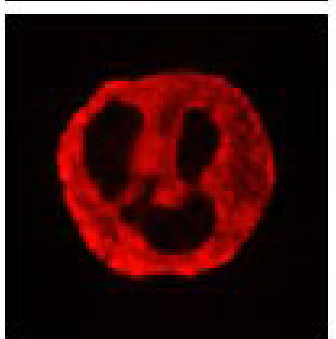

Patient \#2

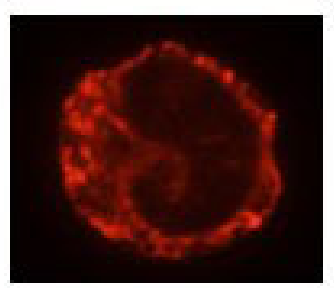

Patient \#3
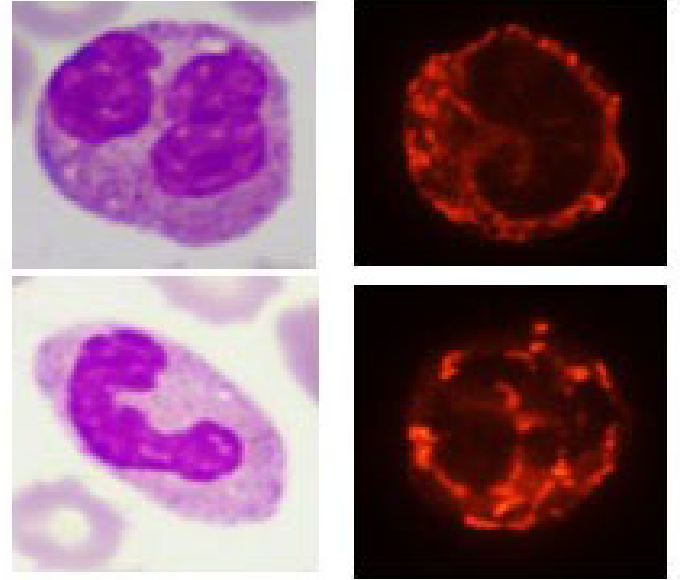

Patient \#4
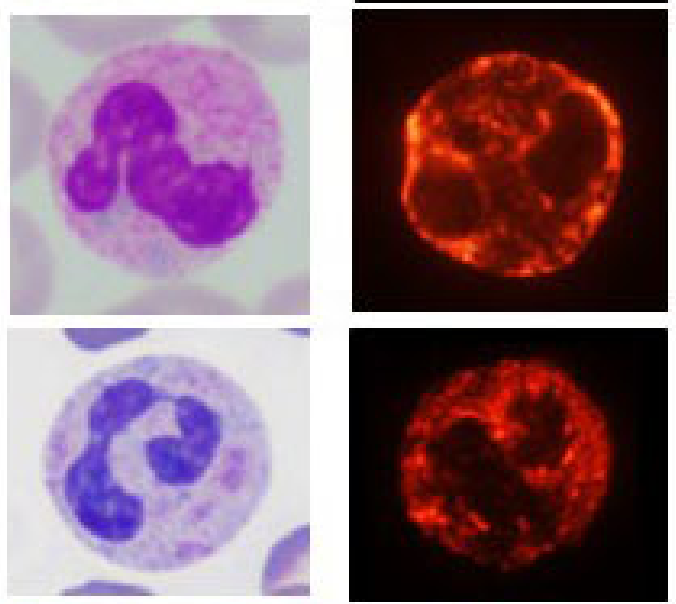

Patient \#5

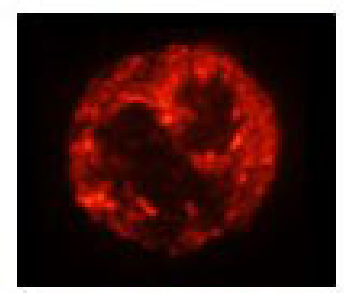

Patient \#6

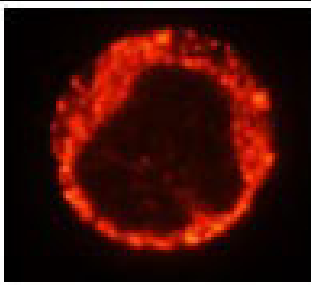

Patient \#7
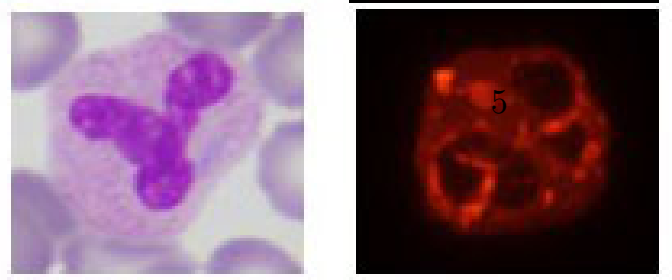

Patient \#8 